\title{
Cost-analysis and cost-effectiveness of physical activity interventions in Brazilian primary health care: a randomised feasibility study
}

\author{
Análise de custo e custo-efetividade de intervenções \\ de atividade física na atenção primária à saúde no Brasil: \\ um estudo de viabilidade randomizado
}

Camila Bosquiero Papini (https://orcid.org/0000-0002-1163-5576) ${ }^{1}$

Leonardo de Campos (https://orcid.org/0000-0002-4600-677X) ${ }^{2}$

Priscila Missaki Nakamura (https://orcid.org/0000-0001-8224-3097) ${ }^{3}$

Bruna Thaís Gomes de Brito (https://orcid.org/0000-0002-7464-543X) ${ }^{4}$

Eduardo Kokubun (https://orcid.org/0000-0002-9404-3444) ${ }^{5}$
${ }^{1}$ Departamento de Ciências do Esporte, Universidade Federal do Triângulo Mineiro (UFTM). Av. do Tutunas 490, Vila Celeste. 38061-500 Uberaba MG Brasil. camila.papini@uftm.edu.br ${ }^{2}$ Programa de PósGraduação em Educação

Física, Universidade Estadual Paulista (UNESP). Rio Claro SP Brasil. ${ }^{3}$ Instituto Federal de

Ciência, Educação e Tecnologia do Sul de Minas Gerais. Muzambinho MG Brasil.

${ }^{4}$ Programa de PósGraduação em Educação Física, UFTM. Uberaba MG Brasil.

${ }^{5}$ Departamento de Educação Física, UNESP. Rio Claro SP Brasil.

\begin{abstract}
Physical exercise programs have been carried out in primary health care in Brazil and have provided good results in terms of effectiveness, their economic contribution has not been investigated yet. The aim of the study is to verify the feasibility of brief counseling physical activity intervention and to compare its economic cost and cost-effectiveness with supervised physical exercise intervention in primary care. A multi-arm parallel feasibility trial, with equal randomization [1:1:1] was conducted in Basic Health Units in Brazil. 61 participants were randomized in Brief Counseling Intervention (BCI), Supervised Physical Exercise Intervention (SPEI) and Control Group (CG). Interventions lasted one year. The $B C I$ is more economical than the SPEI, costing around 50\% less in the economic comparisons (session cost, annual cost and cost per participant annually). At leisure time, the cost to move one person to the physically active category at 12 months is estimated in $R \$ 369.00$ for BCI and $R \$ 426.21$ for the SPEI. The Incremental Cost-effectiveness Ratio (ICER) is $R \$ 310.32$. The BCI is feasible and more economic, however, the cost effective is not that different. Thus, it is strongly recommended that the two interventions be offered at primary care in Brazil.
\end{abstract}

Key words Public health, Brief counseling, Physical exercise
Resumo Programas de exercício físico são ofertados na atenção primária à saúde no Brasil, apresentando bons resultados na eficácia, sua contribuição econômica ainda não foi investigada. $O$ objetivo do estudo é verificar a viabilidade de uma intervenção breve de aconselhamento para atividade física, e comparar seu custo econômico e custo-efetividade com a intervenção supervisionada de exercício físico na atenção primária. Um estudo de viabilidade de múltiplos braços paralelos, com igual randomização [1:1:1] foi realizado em Unidades Básicas de Saúde no Brasil. 61 participantes foram randomizados em Intervenção Breve de Aconselhamento (BCI), Intervenção Supervisionada de Exercício Físico (SPEI) e Grupo Controle (CG). As intervenções tiveram duração de 1 ano. BCI é mais econômica que SPEI, custando cerca de 50\% menos nas comparações econômicas (custo da sessão, custo anual e custo por participante anualmente). No lazer, o custo de mudança de uma pessoa para a categoria fisicamente ativa aos 12 meses é estimado em $R \$ 369,00$ na BCI e $R \$$ 426,21 na SPEI. O Índice de Custo-Efetividade Incremental (ICER) é de R\$310,32. BCI é viável e mais econômica; no entanto, o custo-benefício não é tão diferente. Assim, é altamente recomendável que as duas intervençôes sejam oferecidas.

Palavras-chave Saúde pública, Breve aconselhamento, Exercício fisico 


\section{Introduction}

Noncommunicable Diseases (NCDs) are responsible for approximately $72 \%$ of deaths in Brazil. Around $45 \%$ of the Brazilian population reports at least one NCDs; the incidence of diabetes and hypertension has increased $61 \%$ and $14 \%$, respectively, over the last 10 years and their main risk factors are smoking, harmful use of alcohol, unhealthy diets and physical inactivity ${ }^{1-4}$. Despite being easily preventable, NCDs demand decades of health services use and represent a significant burden over health care costs, which corresponds to a direct cost of more than $\mathrm{R} \$ 7$ billion per year in Brazil ${ }^{5-7}$.

Studies have demonstrated that an investment of US\$ 10 person/year in community programs, fighting physical inactivity, poor nutrition and tobacco, could yield more than US\$ 16 billion in economy of medical costs yearly in five years ${ }^{8}$. The elimination of physical inactivity is estimated to remove from $6 \%$ to $10 \%$ of the main NCDs. Thus, investment in public policies is fundamental to increase the population physical activity levels and reduce the NCDs prevalence.

In addition to considering the effectiveness of health interventions, economic aspects must be regarded as well. International studies have demonstrated the cost-effectiveness and profitability of health interventions when compared to the usual treatment in primary health care, especially when direct supervision or instruction were not required ${ }^{10-12}$. However, the Brazilian public health system has its own needs and peculiarities, which must be considered in terms of intervention cost-effectiveness. Studies comparing costs concerning active and inactive diabetic and hypertensive patients are available in the Brazilian literature ${ }^{13-16}$; however, the economic contribution of physical activity interventions to this population in public health system, has not been investigated in Brazil. Therefore, the evaluation of interventions that have been delivered in primary health care from an economic standpoint and cost-effectiveness will provide relevant information for decision-making regarding the most appropriate program and its further implementation and dissemination.

Less than $40 \%$ of health units provide physical activity programs in primary health care $^{17}$. Most interventions consist in group activities supervised by a health professional and are delivered from 2 to 3 days a week ${ }^{18}$; a workload that can affect adherence and attendance of participants over time. Physical activity counseling interventions appear to be more economically viable once they can be performed in a shorter time in comparison with supervised exercise ones; and can be joined by participants who cannot attend supervised exercise sessions. In primary health care services, counseling practices assume a very relevant character, once its main basis is the strengthening of the subjects' capacity of choice, resulting in an impact on collective health determinants ${ }^{19}$. However, such practice is less commonly used to increase physical activity levels by physical exercise professionals ${ }^{20}$.

Furthermore, supervised and counselling physical activity interventions have provided good results in terms of effectiveness; however, the economic cost and cost-effectiveness of both interventions has not been determined in Brazil yet. Such information would be fundamental for the optimization of financial funds destined to the Brazilian public health system ${ }^{21}$. Experimental studies on this subject would support the elaboration of public policies in Brazil aiming at the expansion and implementation of new programs to promote physical activity ${ }^{22}$, and would allow the comparison of physical activity program costs, outcomes and economic feasibility. Therefore, the aim of the present study is to verify the feasibility of brief counseling physical activity intervention and to compare its economic cost and the cost-effectiveness with supervised physical exercise intervention in primary health care over 1 year.

\section{Methods}

\section{Study design and population}

This is a multi-arm parallel feasibility trial, with equal randomization [1:1:1] conducted in Basic Health Units (BHU) in Brazil. The 1-year intervention of study was conducted in four BHU located in Rio Claro City, São Paulo State, Brazil. Rio Claro City has approximately 201,473 inhabitants, and human development index of 0.803 and GDP per capita of $\mathrm{R} \$ 42,613.74$. The study was approved by the Research Ethics Committee of the Bioscience Institute, UNESP Rio Claro. All participants signed the consent form. The participants, the professionals and the data collectors were not blinded.

The adopted perspective for this study was based on the primary health care of the Brazilian Unified Health System (Public Health System). In Brazil, BHU constitute the so-called "Prima- 
ry Health Care Center", which hosts a wide variety of health professionals and offers health services to the population in a specific region of the city ${ }^{13}$. BHU are administered by local municipality government, which receives resources from the federal government ${ }^{23}$. Health agents are the professionals responsible for working in promotional and preventive health services. They are in charge of family mapping and registry, referral health services, guidance, assistance of families, and for the analysis of obtained information to plan, evaluate and reformulate the local health action plan as well.

A total of four out of seventeen BHU deliver the "Supervised Physical Exercise Intervention" (SPEI) as a health service to the community in Rio Claro City, the reason why these BHU were considered eligible for the study. Besides the Supervised Physical Exercise Intervention, the study proposed a "Brief Counseling Intervention" (BCI) to increase physical activity levels in the four BHU selected. Both interventions were considered for cost-analysis and cost-effectiveness.

The study enrolled adults ( $\geq 18$ years old), from both genders, diabetics and/or hypertensive, with active clinical records at BHU (medical record entries in the last year).

\section{Recruitment of participants}

Given the different particularities of the BHU, the 2-month survey was carried out based on the following sources:

- e-SUS software: computerized registration system of the families living in the territory covered by BHU;

- registration forms: registration of families by health agents;

- clinical records: manual search in the clinical records.

A total of 1,677 families were identified and $30 \%$ of families were randomised from the population $(n=490)$. Random numbers for each family were generated in the random function of Excel Software (Microsoft $\left.{ }^{\circledR}\right)$, and were later classified from the smallest to largest. The first 490 families were selected to the study; however, a total of 307 of them could not been included because they did have an active clinical record or telephone number. From the remaining 183 eligible families, diabetics and/or hypertense adults from both genders were contacted to participate in the study. The contact was made in two ways: a) through 3 phone calls in 3 days and 3 different times; b) through invitation by health agents.
The invitation phase of the participants lasted three months. Seventeen families were not found. Seventy-five families recused to participated. From 91 families included in the study, all adults in the residence within the study inclusion criteria were invited $(n=97)$ and scheduled for the first evaluation (31 participants did not attend the evaluation and 5 participants were excluded because they did not present the diagnosis of diabetes and or hypertension). Thus, 61 individuals (mean age of $57.3 \pm 10.3$ years old) initially participated in the study. They were randomised into Brief Counseling Intervention (BCI, $n=20$, 55.9 \pm 10.1 years old), Supervised Exercise Intervention (SPEI, $\mathrm{n}=23,58.5 \pm 9.4$ years old) and Control Group (CG, n=18, 54.8 \pm 10.6 years old). The randomization process was conducted in the Excel Software (Microsoft ${ }^{\circledR}$ ) and was performed for each BHU. The random function was used to generate random number for each participant. Participants' number were classified from the smallest to largest. The first third was selected for $\mathrm{BCI}$; the second third was select for SPEI; and the last third of participants on the list were selected for CG. The recruitment flowchart is illustrated in Figure 1.

\section{Interventions}

\section{Brief Counseling Intervention}

The participants received an individual counseling with the support of informative and illustrative leaflets based on Transtheoretic Model to change behavior ${ }^{24}$, aiming to increase physical activity levels. The BCI is not part of the health services delivered to population, the reason why it was carried out by researchers and its feasibility is discussed in this paper. The BCI was delivered in 5 face-to-face meetings with approximately 20 minutes long at the BHUs over 1 year. Participants received a different leaflet for each meeting containing specific information:

1- Definition, domains and benefits of physical activity practice;

2- Harmful effects of sedentary behavior and how to reduce it;

3- Moving is what matters;

4- Physical activity intensities and health benefits related with its recommendations;

5- Transposing barriers to establish real goals for PA practice and places that develop free practices in the neighborhood.

All participants received the same information. The sequence of leaflets was maintained, and when any participant missed a meeting, they 


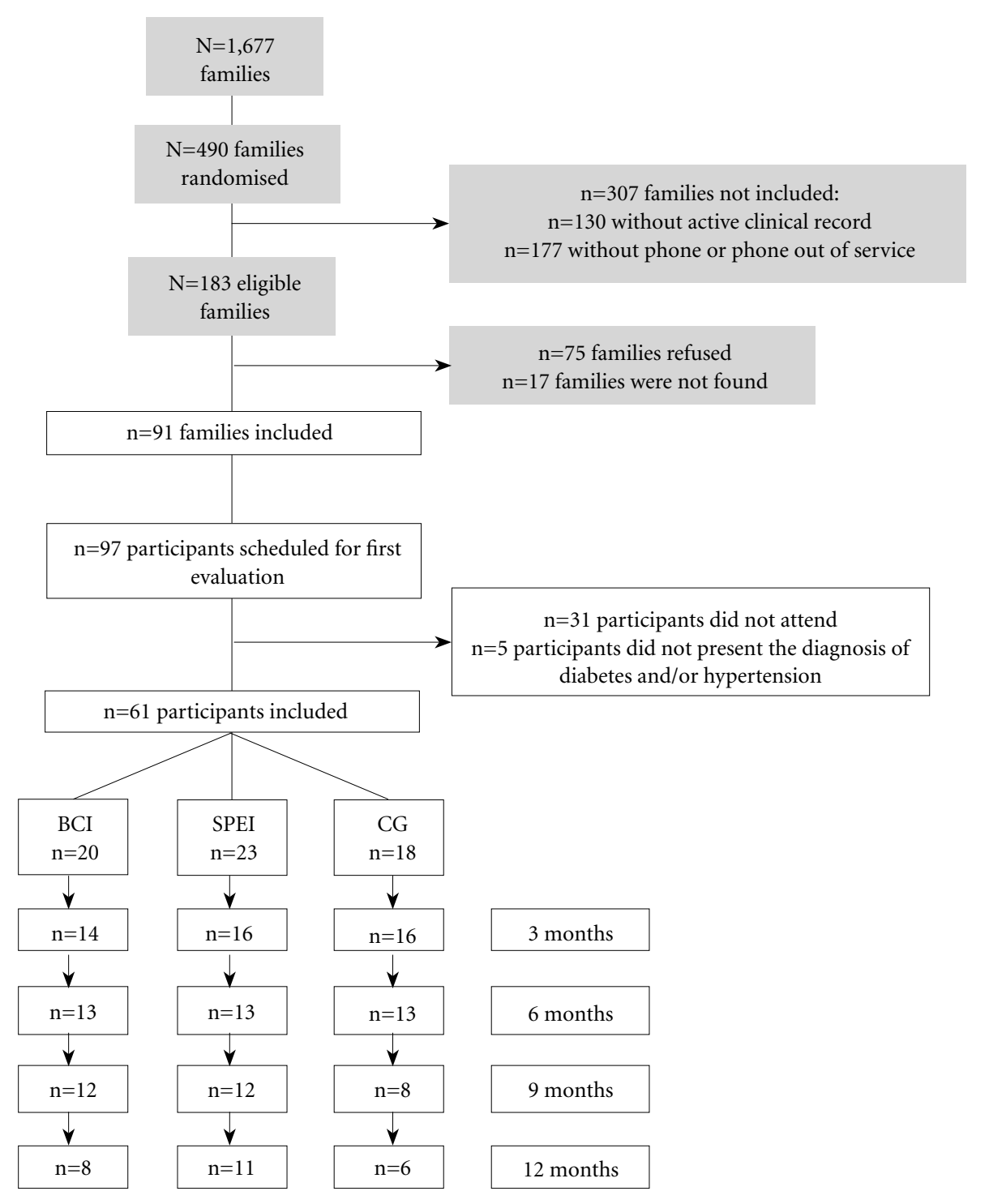

Figure 1. Flowchart of recruitment.

Source: Elaborated by the authors.

received the leaflets and the brief counselling regarding the previous and the present sessions at the same meeting.

\section{Supervised Physical Exercise Intervention}

The participants were invited to join the SPEI delivered by the BHU, carried out by physical education professionals of a multidisciplinary team. The intervention it is part of "Physical Exercise in Health Primary Care Program", which aims to increase physical activity levels and the physical fitness of population ${ }^{25}$. The SPEI offers two 60-min- utes sessions a week of supervised physical exercise from mild to moderate intensity using simple, cheap and sustainable materials (balls, ropes, mats, pet bottles, broom handle) over 1 year.

\section{Control Group}

The participants were advised to maintain daily habits and did not receive any counselling and were not invited to join supervised interventions. They only attended the evaluations over 1 year in the BHU. At the end of the study, they were invited to join the SPEI or the BCI. 


\section{Evaluations and instruments}

The participants from three groups were monitored in 5 times (baseline, 3, 6, 9, and 12 months). They answered a questionnaire concerning personal characteristics (gender, scholar and socioeconomic levels, health and stress perception, physical activity levels). The body weight and stature were measured to calculate the Body Mass Index $\left(\mathrm{BMI}=\mathrm{Kg} / \mathrm{m}^{2}\right)$. The leisure section of the International Physical Activity Questionnaire (IPAQ-long version) was used to evaluate the leisure physical activity levels. The equation used to calculate the total physical activity levels was: $[\text { moderate } \mathrm{PA}+\text { walking }+(2 \mathrm{x} \text { vigorous } \mathrm{PA})]^{26}$. Individuals who reach 150 minutes of physical activity per week were classified as physically active $^{27}$. A single trained researcher performed all assessments.

\section{Cost-analysis of interventions}

The cost-analysis of the interventions was calculated based on the annual cost of the following variables:

1) Cost of Physical Education Professionals: the annual cost considered the sum of salary, food and transportation vouchers, paid leave, Christmas bonus salary and the autarchic social security $(22 \%)$. The Physical Education Professional is a specialist in the prescription and orientation of physical exercises. In this study, they work for the public health system (hired through open public examination) and members of the interdisciplinary professional team of the BHU.

2) Cost of material: cost of five informative leaflets for BCI and cost of balls, ropes, mats (unitary value multiplied by the number of materials) for SPEI.

3) Cost of attendance place: calculated considering the cost of annual maintenance divided by the annual amount of attendance in each BHU. The average cost of the attendance place of the four BHUs was calculated. The maintenance items were: cleaning material, office supplies, printing material, gas, food products, kitchen pantry expenses, medicine, nursing materials, dental materials, oxygen, building maintenance (parts and labor), maintenance equipment (parts and labor), prompt payment expenses, travel expenses, training and courses expenses, rental fees, electricity, landline and cell phone, security guard, fuel, vehicle maintenance, medical shifts and laundry expenses.
Posteriorly, the session cost of each intervention was calculated using the following equation:

$$
\begin{aligned}
\text { Session cost }= & \text { PEP hourly pay }+ \text { material cost }+ \\
& \text { attendance place cost }
\end{aligned}
$$

1) Cost of the physical education professional hourly pay: the annual cost of the physical education professional was divided by the number of months of a year. As the professional has a workload of 40 hours/week, the dividing factor 200 was applied, in accordance with the 58 article of CLT (Brazilian Consolidation of Labor) and precedent 431 of TST (Superior Labor Court). Posteriorly, the value was divided by the number of sessions offered in 1 hour. For the SPEI, the dividing factor was 1 , once the session lasts $60 \mathrm{~min}$ utes. The dividing factor 3 was used for the BCI, since each session lasts 20 minutes. The following equation was used:

PEP hourly $=\frac{(\text { PEP annual cost } \div 12 \text { months }) \div 200}{\text { nay }}$
number of sessions per hour

2) Cost of material per session: calculated considering the material cost of the interventions divided by the number of sessions offered per year. The SPEI offers in average 84 annual sessions (in 10.5 months, excluding vacation and holidays), while the BCI offers 5 annual sessions. The following equation was used:

Material cost $=\frac{\text { material cost }}{\text { per session }}$

To facilitate the comparison of the session costs, the length of the interventions was equalized in 60 minutes. Once the BCI offers 3 sessions of 20 minutes in 60 minutes, the material cost was multiplied by 3 and the session cost of the SPEI was represented by the hourly pay.

Additionally, the annual cost of the interventions and the annual cost per participant served in each intervention were calculated as follows:

1) Annual cost of the interventions: was calculated by multiplying the session cost by the number of sessions offered:

$$
\begin{aligned}
\text { Annual cost }= & \text { session cost } x \text { number of sessions } \\
& \text { per year }
\end{aligned}
$$

2) Annual cost per participant: calculated by dividing the annual cost of the intervention by the number of participants: 
Annual cost $=\frac{\text { annual cost of the intervention }}{\text { number of participants }}$
per participant

The SPEI was attended by 23 participants in 84 sessions during the year of the present research. The BCI was attended by 20 participants, and each participant attended 5 sessions per year (20 minutes), in a total of 100 annual sessions. All cost analyses were performed considering the Brazilian currency (real R\$).

\section{Cost-effectiveness of interventions}

The cost-effectiveness of interventions was calculated based on the following equations:

1) Cost per minute of physical activity: calculated by dividing the annual cost of each intervention (BCI and SPEI) by the delta of the physical activity level. The following equation was used:

Cost of $P A$

per minute $=\frac{\text { annual cost of the intervention }}{\text { final } P A-\text { initial } P A}$

2) Increased physical activity cost: calculated by dividing the annual cost of each intervention (BCI and SPEI) by the number of participants who increased physical activity level in one year, using the following equation:

$$
\uparrow P A \text { cost }=\frac{\text { annual cost of the intervention }}{\text { number of participants who }}
$$

3) Start or keep physically activity recommendation cost: calculated dividing the annual cost of each intervention (BCI and SPEI) by the number of participants who became more active or maintained the physical activity levels (physically activity levels of 150 minutes per week) in one year, using the equation: $\begin{aligned} & P A \\ & \text { levels } \\ & \text { cost }\end{aligned}=\frac{\text { annual cost of the intervention }}{\text { number of physically active participants }}$

4) Incremental cost-effectiveness ratio (ICER): The cost-effectiveness comparison was performed through the ICER, subtracting the SPEI and the BCI costs, and dividing the result by the subtraction of the SPEI and the BCI effectiveness. The effectiveness considered the minutes increased in the physical activity levels in each intervention $($ delta $=$ final PA- initial PA). The following equation was used:
$I C E R=\frac{\text { SPEI cost }- \text { BCI cost }}{\text { SPEI effectiveness }- \text { BCI effectiveness }}$

The annual cost of intervention was considered in all the calculations. All the cost effectiveness analyses were performed using the Brazilian currency (real- R\$).

\section{Statistical analysis}

The descriptive analysis was performed for the categorical variables (prevalence and 95\% confidence interval) and the continuous variables (mean and standard deviation). The cost-analysis and cost-effectiveness are presented through descriptive analysis, presenting the calculations and their respective results. The Kruskal-wallis $\mathrm{H}$ test was used to compare the baseline variables between the groups and the categorical variables (pairwise comparisons were performed using a Bonferroni correction for multiple comparisons). The continuous variable (Bonferroni posthoc) was analyzed conducting one-way ANOVA. The analyses were performed using statistical program SPSS $21.0(\mathrm{p}<0.05)$. Due to the dropouts occurred over the 12 months, the physical activity outcomes were estimated using an intent-to-treat analysis with baseline values carried forward.

\section{Results}

The mean age of the initial sample was 57.3 $( \pm 10.03)$ years old. Table 1 show the characteristics of the groups in the beginning of the study. In all the groups, most participants are women, aged 40-60 years old, less than 4 years of study, classified as overweight or obese, with good health perception, mild to moderate stress levels. In all the groups, most participants did not perform physical activities in leisure at the baseline. The statistical analysis showed differences in the proportion of socioeconomic level $(p=0.023)$, indicating that the proportion of the CG are classified as belonging to class $B$ to $C(p=0.03)$ in comparison with groups BCI and SPEI. No differences were found for the other variables regarding the proportion of the groups $(\mathrm{p}>0.05$, Table 1).

We emphasize that, in all the groups, the average BMI was equal of higher than $30 \mathrm{~kg} / \mathrm{m}^{2}$, indicating obesity. The participants from all groups presented low averages of minutes regarding leisure activity per week. The sedentary behavior 
Table 1. Initial characteristics (categorical variables) of the participants stratified by groups.

\begin{tabular}{|c|c|c|c|c|}
\hline \multirow{2}{*}{ Categorical Variables } & BCI $(n=20)$ & SEI $(n=23)$ & CG $(n=18)$ & Kruskal-wallis \\
\hline & $\%$ & $\%$ & $\%$ & p-value \\
\hline \multicolumn{5}{|l|}{ Gender } \\
\hline Female & 80 & 83 & 72 & 0,716 \\
\hline Male & 20 & 17 & 28 & \\
\hline \multicolumn{5}{|l|}{ Age } \\
\hline 18 to 39 years old & 0 & 8 & 6 & 0,472 \\
\hline 40 to 60 years old & 65 & 48 & 72 & \\
\hline$\geq 61$ years old & 35 & 44 & 22 & \\
\hline \multicolumn{5}{|l|}{ Arterial Hypertension } \\
\hline Yes & 100 & 91 & 100 & 0,186 \\
\hline No & 0 & 9 & 0 & \\
\hline \multicolumn{5}{|l|}{ Diabetes Mellitus } \\
\hline Yes & 40 & 35 & 50 & 0,618 \\
\hline No & 60 & 65 & 50 & \\
\hline \multicolumn{5}{|l|}{$\mathrm{AH}$ and $\mathrm{DM}$} \\
\hline Yes & 40 & 26 & 50 & 0,289 \\
\hline No & 60 & 74 & 50 & \\
\hline \multicolumn{5}{|l|}{ Socioeconomic levels } \\
\hline A & 65 & 61 & 29 & 0,023 \\
\hline $\mathrm{B}$ and $\mathrm{C}$ & 35 & 35 & 55 & \\
\hline $\mathrm{D}$ and $\mathrm{E}$ & 0 & 4 & 16 & \\
\hline \multicolumn{5}{|l|}{ Education levels } \\
\hline$\leq 4$ years & 60 & 48 & 61 & 0,439 \\
\hline 5 to 8 years & 15 & 9 & 11 & \\
\hline$\geq 9$ years & 25 & 30 & 11 & \\
\hline${ }^{\star}$ Missing & 00 & 13 & 17 & \\
\hline \multicolumn{5}{|l|}{ Daily stress } \\
\hline No stress & 25 & 9 & 6 & 0,385 \\
\hline Light to moderate & 55 & 69 & 67 & \\
\hline High & 20 & 22 & 27 & \\
\hline \multicolumn{5}{|l|}{ Nutritional status } \\
\hline Normal & 10 & 17 & 11 & 0,327 \\
\hline Overweight & 30 & 35 & 17 & \\
\hline Obesity & 60 & 48 & 72 & \\
\hline \multicolumn{5}{|l|}{ Health perception } \\
\hline Excellent and very good & 10 & 13 & 17 & 0,908 \\
\hline Good & 75 & 70 & 55 & \\
\hline Poor and very poor & 15 & 17 & 28 & \\
\hline \multicolumn{5}{|l|}{ Leisure PA classification } \\
\hline Physically active & 20 & 5 & 33 & 0,668 \\
\hline Insufficient active & 15 & 39 & 11 & \\
\hline Do not practice & 65 & 56 & 56 & \\
\hline \multirow{2}{*}{ Continuous Variables } & BCG $(n=20)$ & SEG $(n=23)$ & CG $(n=18)$ & ANOVA \\
\hline & Average (sd) & Average (sd) & Average (sd) & p-value \\
\hline Age (years old) & $55,9 \pm 10,1$ & $58,5 \pm 9,4$ & $54,8 \pm 10,6$ & 0,478 \\
\hline BMI $\left(\mathrm{kg} / \mathrm{m}^{2}\right)$ & $31,4 \pm 5,8$ & $30,9 \pm 5,7$ & $32,8 \pm 6,0$ & 0,578 \\
\hline WHR & $0,85 \pm 0,1$ & $0,91 \pm 0,1$ & $0,88 \pm 0,1$ & 0,079 \\
\hline Leisure PAL (min. week ${ }^{1}$ ) & $43,5 \pm 75,0$ & $37,0 \pm 76,5$ & $82,5 \pm 124,5$ & 0,265 \\
\hline SB at week day (min) & $224,5 \pm 181,5$ & $171,9 \pm 111,2$ & $169,4 \pm 136,3$ & 0,402 \\
\hline SB at weekend day (min) & $247,5 \pm 141,7$ & $198,2 \pm 119,2$ & $197,2 \pm 131,4$ & 0,383 \\
\hline
\end{tabular}

BCG=Brief Counseling Group; SEG=Supervised Physical Exercise Group; CG=Control Group; $A H=$ Arterial Hypertension; DM=Diabetes Mellitus; PA=Physical Activity; BMI=Body Mass Index; WHR=Waist Hip Ratio; PAL=Physical Activity Levels; $\mathrm{SB}=$ Sedentary Behavior. 
pattern is similar when comparing a weekday and a weekend day (Table 1). Figure 1 illustrates the losses into follow-up after randomization for each point (3, 6, 9 and 12-month).

Table 2 presents the annual calculation of the variables used for the economic analysis equations and the calculations of the economic analysis and cost-effectiveness. The Physical Education Professional costs R \$39,801.64 per year to the Municipal Health Foundation, considering the salary, taxes and benefits. The mean of the attendance place cost for the four BHU included in the research is $\mathrm{R} \$ 4.79$. The annual material cost of the BCI and the SPEI is $\mathrm{R} \$ 3.75$ and $\mathrm{R} \$ 336.00$, respectively (Table 2 ).

The Physical Education Professional hourly pay for the SPEI is $\mathrm{R} \$ 16.58$ (60-minute session) and $\mathrm{R} \$ 5.53$ for the BCI (20-minute session). The cost of material per session is $R \$ 4.00$ and $R \$ 0.75$ respectively. The calculation of the session cost for the interventions point to an expense of $\mathrm{R} \$$ 25.37 for the SPEI and R\$11.07 for the 20-min- ute sessions of the BCI. Equalizing the length of the sessions (60 minutes), the cost of the BCI is $\mathrm{R} \$ 23.62$, i.e., only $\mathrm{R} \$ 1.75$ more economic; however, it offers much fewer sessions per year when compared with the SPEI. Thus, considering the number of sessions offered annually by each intervention, the cost of the SPEI is $\mathrm{R} \$ 2,131.08$ per year and the cost of the BCI is $\mathrm{R} \$ 1,107.00$ per year (Table 2). For the BCI, 100 sessions per year (20 minutes) were needed to attend the $20 \mathrm{BCI}$ participants.

The $\mathrm{BCI}$ is also more economic when the annual cost per participant is considered. In the present study, the SPEI served 23 participants, while the BCI served 20 participants during the year. Calculating the cost of the interventions per participant, they cost $\mathrm{R} \$ 92.65$ and $\mathrm{R} \$ 55.35$ respectively. Considering that the SPEI is already offered to public health service users, it serves an average of 30 participants per group, which represents an actual cost of R\$71.03 per user (Table 2).

Table 2. Annual calculation of the variables used for the economic analysis equations and cost analysis and costeffectiveness of interventions.

\begin{tabular}{|c|c|c|c|c|c|c|}
\hline \multicolumn{7}{|c|}{ Annual calculation of the variables used for the economic analysis equations } \\
\hline \multirow{8}{*}{$\begin{array}{l}\text { Annual cost } \\
\text { of PEP }\end{array}$} & \multicolumn{2}{|c|}{ Items } & & \multicolumn{2}{|c|}{ Calculation } & \multirow[t]{2}{*}{ Total } \\
\hline & & & \multicolumn{2}{|l|}{ Monthly (R\$) } & Annual (R\$) & \\
\hline & Salary & & $2,250.41$ & & $27, .004 ., 92$ & \\
\hline & Transp & voucher & 0.00 & & 0.00 & \\
\hline & Food v & & 280.00 & & $3,360.00$ & $\mathrm{R} \$ 39,801.64$ \\
\hline & $1 / 3 \mathrm{vaca}$ & & --- & & 750.14 & \\
\hline & Christn & Is salary & --- & & $2,250.41$ & \\
\hline & INSS $(2$ & & 495.09 & & $6,436.17$ & \\
\hline \multirow{6}{*}{$\begin{array}{l}\text { Annual } \\
\text { cost of } \\
\text { attendance } \\
\text { place }\end{array}$} & & & $\begin{array}{c}\text { Maintenance } \\
(\mathrm{R} \$)\end{array}$ & $\begin{array}{l}\text { Amount of } \\
\text { attendance }\end{array}$ & $\begin{array}{c}\text { Maintenance/ } \\
\text { amount of } \\
\text { attendance }\end{array}$ & Total \\
\hline & BHU 1 & & $123,755.24$ & 30.293 & 4.09 & \multirow{5}{*}{$\mathrm{R} \$ 4.79$} \\
\hline & BHU 2 & & $204,157.48$ & 45.511 & 4.49 & \\
\hline & BHU 3 & & $117,990.27$ & 18.104 & 6.52 & \\
\hline & BHU 4 & & $123,756.24$ & 30.293 & 4.09 & \\
\hline & & & & & Average $=4.79$ & \\
\hline \multirow{5}{*}{$\begin{array}{l}\text { Annual cost } \\
\text { of material }\end{array}$} & \multicolumn{3}{|c|}{ Unitary value (R\$) } & $\begin{array}{c}\text { Number of } \\
\text { materials }\end{array}$ & $\begin{array}{c}\text { Value } \mathrm{x} \\
\text { materials }\end{array}$ & Total \\
\hline & BCI & Leaflets & 0.75 & 5 & 3.75 & $\mathrm{R} \$ 3.75$ \\
\hline & SPEI & Ball & 8.80 & 10 & 88.00 & \multirow{3}{*}{$\mathrm{R} \$ 336.00$} \\
\hline & & Rope & 7.50 & 10 & 75.00 & \\
\hline & & Mats & 17.30 & 10 & 173.00 & \\
\hline
\end{tabular}


Table 2. Annual calculation of the variables used for the economic analysis equations and cost analysis and costeffectiveness of interventions.

\begin{tabular}{|c|c|c|}
\hline \multicolumn{3}{|c|}{ Cost analysis and cost-effectiveness of interventions } \\
\hline Variables & Calculation & Cost $(\mathbf{R} \$)$ \\
\hline PEP hourly pay & $\begin{array}{l}{[(\mathrm{PEP} \text { annual cost } \div 12 \text { months }) \div 200] \div \text { number of }} \\
\text { sessions per hour }\end{array}$ & \\
\hline SPEI (60 min) & $(39,801.64 \div 12) \div 200 \div 1$ & 16.58 \\
\hline $\mathrm{BCI}(20 \mathrm{~min})$ & {$[(39,801.64 \div 12) \div 200] \div 3$} & 5.53 \\
\hline Material cost per session & material cost $\div$ number of sessions per year & \\
\hline SPEI & $336 \div 84$ & 4.00 \\
\hline BCI & $3.75 \div 5$ & 0.75 \\
\hline Session cost & PEP hourly pay + material cost + attendance place & \\
\hline SPEI $(60 \mathrm{~min})$ & $16.58+4.00+4.79$ & 25.37 \\
\hline BCI (20 min) & $5.53+0.75+4.79$ & 11.07 \\
\hline $\mathrm{BCI}(60 \mathrm{~min})$ & $16.58+\left(0.75^{\star} 3\right)+4.79$ & 23.62 \\
\hline Annual cost & session cost $\mathrm{x}$ number of sessions per year & \\
\hline SPEI $(60 \mathrm{~min})$ & $25.37 \times 84$ & 2.131 .08 \\
\hline BCI $(20 \mathrm{~min})$ & $11.07 \times 100$ & 1.107 .00 \\
\hline Annual cost per participant & annual cost of the intervention $\div$ number of participants & \\
\hline SPEI $(60 \mathrm{~min})$ & $2,131.08 \div 23$ (participants of research) & 92.65 \\
\hline SPEI (60 min) & $2,131.08 \div 30$ (service's users) & 71.03 \\
\hline BCI (20 min) & $1,107.00 \div 20$ & 55.35 \\
\hline Cost of PA per minute & annual cost of the intervention $\div$ (final PA - initial PA) & \\
\hline SPEI & $2,131.08 \div(63.3-37.0)$ & 81.02 \\
\hline $\mathrm{BCI}$ & $1,107.00 \div(63.5-43.5)$ & 55.35 \\
\hline Increased PA cost & $\begin{array}{l}\text { annual cost of the intervention } \div \text { number of } \\
\text { participants who increased PA levels }\end{array}$ & \\
\hline SPEI & $2,131.08 \div 8$ & 266.38 \\
\hline BCI & $1,107.00 \div 5$ & 221.4 \\
\hline Start or keep PA recommendation cost & $\begin{array}{l}\text { annual cost of the intervention } \div \text { number of physically } \\
\text { active participants }\end{array}$ & \\
\hline SPEI & $2,131.08 \div 5$ & 426.21 \\
\hline BCI & $1,107.00 \div 3$ & 369.00 \\
\hline ICER & (SPEI - BCI cost $) \div($ SPEI - BCI effectiveness $)$ & \\
\hline & $(2,131.08-1,107) \div(23.3-20.0)$ & 310.32 \\
\hline
\end{tabular}

INSS=autarchic social security (22\%); BHU=Basic Health Units; BCI=Brief Counseling Intervention; SPEI=Supervised Physical Exercise Intervention; PEP=Physical Education Professional; PA=Physical Activity; ICER=Incremental Cost-effectiveness Ratio.

Source: Elaborated by the authors.

Therefore, the BCI is more economic in all aspects - session cost, annual cost and cost per participant, costing around $50 \%$ less of the SPEI. Although the BCI has been proven more economic in all the analysis, it is necessary to consider and compare the cost-effectiveness of the interventions, as well as the feasibility of such service offered by the Brazilian public health system.

Figure 2 illustrates the physical activity outcomes used to calculate the cost-effectiveness. The leisure domain presented an increase in min- utes per week of physical activity level in the BCI and SPEI; however, the CG had a decrease. Concerning the prevalence of physical activity level status, comparing the baseline and the end of the interventions, most of the participants from the 3 groups maintained their physical activity levels. It is important to emphasize that any alteration (at least 1 minute of practice added in the post intervention evaluation in comparison with the pre-intervention evaluation) was considered for physical activity increase. Although the average of the min.week ${ }^{-1}$ of the participants belonging 


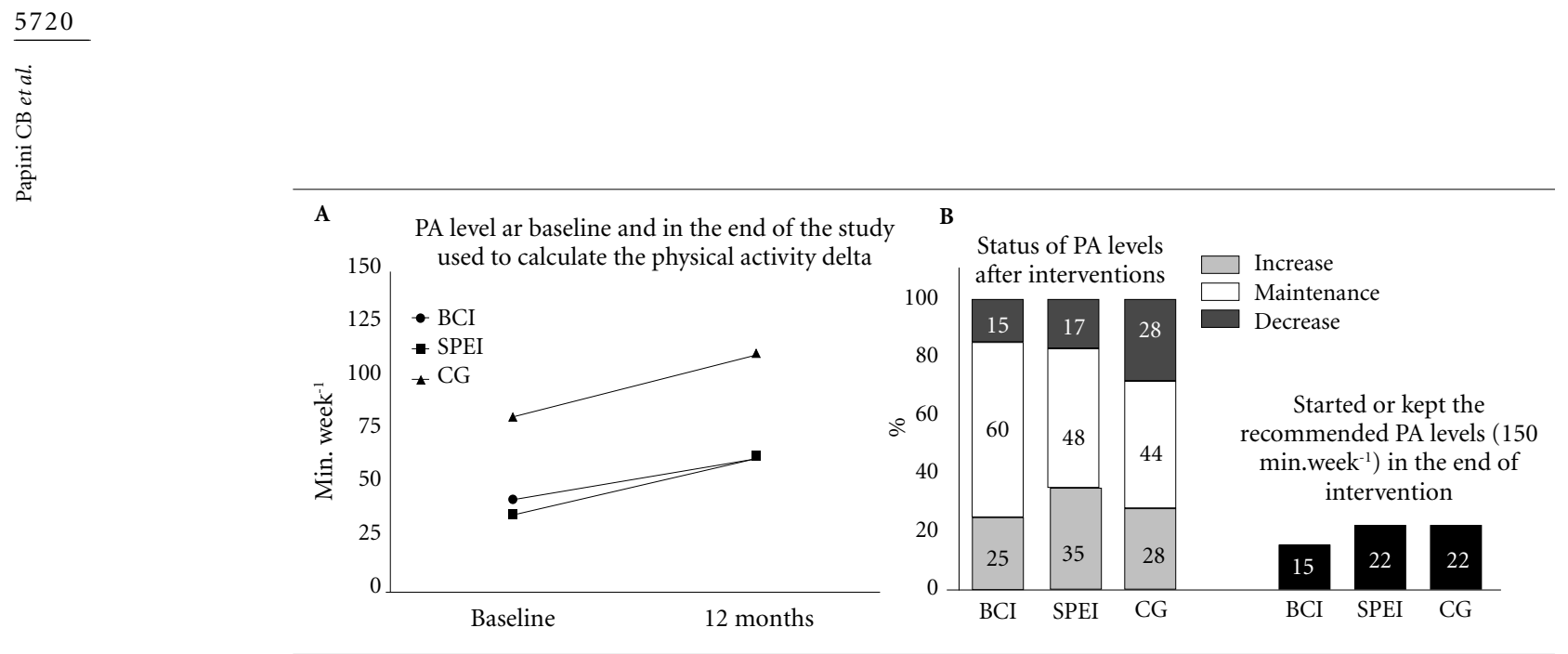

Figure 2. Physical activity outcomes.

Source: Elaborated by the authors.

to groups BCI and SPEI and the prevalence of increase in physical activity levels in leisure had improved, few participants reach the minimum recommended physical activity level per week (150 minutes). In the group BCI, 15\% of the participants reached the recommendation in leisure time in the end of the 1-year. For the groups SPEI and CG, the prevalence of physically active participants in leisure is a little higher than the BCI (22\% for both groups).

According to Table 2, the BCI was shown to be a little more cost-effective in all the analyses. In the leisure domain, the cost-effectiveness of the BCI per minute of activity is $31.7 \%$ lower than SPEI. When comparing the cost-effectiveness of physical activity increased and start/keep the recommended physical activity level, the cost represents $17 \%$ and $13.4 \%$ lower than SPEI value, respectively.

At leisure time, the cost to move one person to the physically active category at 12 months is estimated in $\mathrm{R} \$ 369.00$ for the $\mathrm{BCI}$ and $\mathrm{R} \$ 426.21$ for the SPEI. The cost to increase any amount of physical activity level at leisure time is estimated in $\mathrm{R} \$ 221.4$ for the BCI, costing $\mathrm{R} \$ 55.35$ per minute of physical activity. These costs are estimated in $\mathrm{R} \$ 226.38$ and $\mathrm{R} \$ 81.02$, respectively, for the SPEI. The ICER is R $\$ 310.32$.

Finally, it is important to consider the feasibility of the BCI, once it is not usually offered by the physical education professionals who work for the Brazilian public health system. Only 25 participants of the research attended the 5 evaluations, which represents $41 \%$ of the initial sample. The highest dropout rate occurred between the baseline and the third month for the groups
BCI (30\%) and SPEI (30\%). The CG showed the highest dropout rate in the sixth month (28\%). In the end of 1 year, the dropout rates of the groups BCI, SPEI and CG were $60 \%, 52 \%$ and $67 \%$, respectively (Figure 1).

\section{Discussion}

In Brazil, only $39 \%$ of the adult population achieve the sufficient physical activity level for health at leisure time ${ }^{4}$. Currently, there is abundant evidence that links physical inactivity to increased risk for numerous $\mathrm{NCDs}^{9,28}$. To combat physical inactivity, an important tool for research and practice has been the promotion of physical activity through primary care ${ }^{29}$. Over the last years, public policies have been implemented focusing on health promotion and support of physical activities actions in the primary care services in Brazil ${ }^{30}$. Several programs have been carried out in this contex $\mathrm{t}^{17}$, although some of these have presented good results in terms of effectiveness, little is known about their economic cost and cost-effectiveness.

According to our results, in economic comparisons (session cost, annual cost and cost per participant annually), the BCI is more economical than the SPEI, costing around 50\% less. When the duration of the sessions is equalized to 60 minutes, the cost session of the interventions is roughly the same; however, the BCI offers only 5 sessions per year, while the SPEI offers 84 sessions. On the other hand, the $\mathrm{BCI}$ serves 3 people per session (60 minutes), while the SPEI serves up to 30 people per session. Therefore, it is im- 
portant to ponder the annual cost of intervention considering the number of sessions required to serve the participants of the research.

The BCI had to offer 100 sessions (of 20 minutes) to serve the 20 participants of the $\mathrm{BCI}$, while the SPEI offered 84 sessions to serve the 23 participants of the SPEI. Even considering the sessions offered for both interventions, the BCI is still around 50\% more economical than the SPEI. Finally, the BCI is also more economic when the annual cost per participant was considered. To the optimization of financial funds destined to the Brazilian public health system, public administrators must consider the economic analysis of interventions.

According to the investigation of the National Health Survey in Brazil, NCDs carriers make more use of health services than healthy peo$\mathrm{ple}^{7}$. However, studies have demonstrated that the physical activity levels have influence in the cost and expenses in Brazilian hypertensive and diabetic patients. It is estimated an economy of R\$ 6,500.00 annually for every 100 physically active diabetics ${ }^{14}$. The implementation of a supervised physical exercise program contributes to an economy of R $\$ 2,700.00$ for every 100 hypertensive participants who become physically active ${ }^{31}$. These economies are related to the reduction of consultations, medications and other services in the primary care and specialized health centers. Faced with theses evidences, it is important to make hypertensive and diabetic individuals physically active. To implement effective physical activity interventions on a broad population basis, their cost-effectiveness needs to be evaluated as well.

The calculations performed in this study indicated that the BCI is a little more cost effective than the SPEI. Despite the prevalence of participants who increased physical activity levels and the increased of minutes spent in physical exercise per week, few participants from both groups (BCI and SPEI) reached the minimum recommendation of physical activity (150 minutes weekly). The costs to start or keep physically active in leisure time (150 minutes weekly) in the BCI represents $86 \%$ of the SPEI costs.

According to Anokye et al. ${ }^{10}$, brief advice is a cost-effective way to improve physical activity among adults. Garret et al. ${ }^{12}$ highlight that most interventions to increase physical activity were cost-effective, especially where direct supervision or instruction was not required. Walking, exercise groups, or brief exercise advice on prescription delivered in person, or by phone or mail, appeared to be more cost-effective than supervised gym-based exercise classes or instructor-led walking programs. Brief interventions promoting physical activity in primary care and in community are likely to be inexpensive compared with usual care ${ }^{11}$.

Some studies have demonstrated that the cost-effectiveness of interventions in primary care $^{32-34}$. For example, the systematic review conducted by Garret et al. ${ }^{12}$, which aimed to assess the cost-effectiveness of physical activity interventions in primary care and the community, have demonstrated that the cost-effectiveness ratios for moving one inactive person to an active stage at 12 months varied from approximately 331 to 3673 . To be included, studies had to be perform an economic analysis of lifestyle interventions including physical activity advice and/ or programs for adults, based in either primary care or the community, using general study populations or those with conditions known to be improved by physical activity, and a follow-up period of at least 6 months.

Another systematic review to determine whether brief interventions promoting physical activity are cost-effective in primary care or community settings was carried out by Vijay et al. ${ }^{11}$. They found that incremental cost of moving an inactive person to an active state, estimated for eight studies, ranged from approximately $\mathfrak{E} 96$ to $\mathfrak{E} 986$ and concluded that brief interventions promoting physical activity in primary care and in community are likely to be inexpensive compared with usual care. In this study, the eligible criteria for type of intervention were: interventions involving verbal advice, encouragement, negotiation or discussion, delivered face-to-face in a single session or multiple brief sessions, with or without additional non-face-to-face contacts (e.g., leaflets or phone calls) or interventions that were reported as "brief" or "minimal", and aimed to increase physical activity at the individual level (i.e., brief interventions delivered to individuals or groups).

All studies mentioned randomized controlled trials in large scale, considering the recommendation of 30 minutes of physical activity at least 5 days in a week. Furthermore, authors reported that interventions, study populations, study designs infrastructures, funding models, and cost structures were heterogeneous, making comparisons difficult between different countries. Most studies were performed in the United States, United Kingdom, Australia and New Zealand, which have different peculiarities regard- 
ing services of public health compared to Brazil. Despite this, the interventions evaluated in the present study seem to be more cost effective than those presented by the authors.

It is also important to consider the feasibility of the $\mathrm{BCI}$, once it is not a usual service offered to population by Physical Education Professionals in Rio Claro city. Around 75\% of the Brazilian population is covered exclusively by Brazilian public health ${ }^{35}, 87$ million Brazilians are accompanied by 27,000 Family Health Teams ${ }^{36}$ in $92 \%$ of Brazilian municipalities, making this an ideal setting for intervening to increase physical activity levels. The National Institute for Health and Care Excellence ${ }^{37}$ has recommended brief advice in primary care as an effective way of increasing physical activity levels. In addition, the US Preventive Services Task Force recommends that clinicians advise adults to engage in physical activity for the prevention of cardiovascular disease ${ }^{38}$.

Our results indicated that the dropout regarding the BCI and the SPEI are similar between the baseline and the third month (30\%). At the end of one year, the dropout is $60 \%$ for the BCI and $52 \%$ for the SPEI. Antunes et al. ${ }^{39}$ reported a rate adherence of $62.5 \%$ in a counseling physical exercise program in Brazilian primary health care (Active Life Improving Health, VAMOS). It is a high rate comparing to our study (rate adherence of $40 \%$ ); however, the intervention in our study lasted 1 year, while the VAMOS lasts only 3 months. Santos et al..$^{40}$ found that only a small number of participants remain for more than five years in a community physical activity program in Brazil. They also found that the highest number of dropouts occurred in the first 12 months of participation, with the highest rates observed in the third month, which was identified as a critical period for permanence, corroborating our results.

To help people maintain the physical activity behavior change, it is necessary to give more support to encourage participants to overcome the barriers, mainly in the first months of participation. From an economic perspective, the decision to engage in physical activity can be viewed as a decision involving an intertemporal trade-off between current costs (e.g., time and energy expenditure) and future benefits (e.g., improved health $)^{29}$. The trade-off of physical activity involves time and risk preferences. Individuals who are willing to "pay" the immediate costs of physical activity to obtain health in the future are regarded as having patient time preferences ${ }^{29}$. As with time preferences, individuals vary in the degree to which they avoid (or seek out) risk, and their ability to accurately assess risk. Individuals who have a greater degree of tolerance for risk have been found to be more likely to engage in physical activity ${ }^{41}$. However, in general, most individuals possess impatient time and risk preferences $^{29}$.

Despite physical activity promotion through primary care is considered an important strategy, other possibilities should be considered, such as public policies to achieve all the population. According to a systematic review conducted by Laine et al. ${ }^{42}$ improving opportunities for walking and biking seems to be a cost-effective way to increase physical activity.

A strength of the current study is the inclusion of cost-effectiveness analysis that were based on randomized controlled trial. However, estimates of cost-effectiveness are likely to be conservative because of the small number of participants who completed all interventions. Another relevant point of the present study is the 1-year long-term of interventions. According to Roux et al. ${ }^{43}$, economic analysis suggests the cost-effectiveness of physical activity interventions may be even more favorable when long time horizons are taken into account. In addition, the study evaluated the cost-effectiveness of a service that is already delivered to the population by Physical Education Professionals (in most Brazilian studies, the SPEI is delivered by researchers), and the feasibility and cost-effectiveness evaluations of a new possibility of intervention (brief counseling) to be implemented in public health system. To the best of our knowledge, this is the first study to consider the economic and effectiveness-cost analysis of brief counseling and supervised physical exercise intervention in Brazilian primary care.

On the other hand, limitations should be considered as well. The physical activity levels were accessed through questionnaire. In general, physical activity questionnaires tend to underestimate the time spent in activities performed in some positions and overestimate efforts with moderate to vigorous intensity. Some individuals have difficulties to report the intensity and duration of unorganized activities and to report activities carried out in the past. However, the physical activity self-reports using questionnaires are particularly important in order to identify, with the greatest degree of fidelity possible, the context in which physical activity occurs, for example, the leisure time and types of transportation. In addition, we were expected to have more participants in the study and the combination between direct 
and indirect measures would be very expensive for the study financial resources.

The small number of participants was due to difficulties found in the recruitment and invitation phase of study, which lasted 5 months. Each BHU has different registration methods of the families attended in public health service. However, many records do not have the telephone number or other source of contact. A factor that made the invitation phase of the study difficult was the researchers' phone contact. They mentioned the possible allocation in the interventions to increase physical activity. People are usually reluctant to come to any consultation if they expect to be "told off". The method of invitation should be designed to not mention any information about physical activity or exercise; however, the ethics committee would not approve it. This study also showed a higher proportion of women attending both interventions. One reason for that would be men's objection to primary health care, seeking for health assistance only when diseases are already established, what makes them less adept at physical activity programs ${ }^{44,45}$. Different methods for recruiting and maintaining men to such interventions need to be identified. Finally, there was a large dropout of participants over 1 year of intervention (BCI and SPEI). The investigation of the reasons for dropouts was not adopted during the study, making it impossible to explore this information.

Interventions to increase physical activity levels are recommended as a public health service. Despite the variability in the quantity and quality of evidence on intervention effectiveness in the literature and uncertainty about the longterm sustainability of behavioral changes, it is highly likely that the interventions addressed in the present study could lead to substantial improvement in the population health while saving health care resources.

\section{Conclusion}

The analysis indicated that The BCI is more economical than the SPEI. The results of the cost-effectiveness analysis suggested small differences between BCI and SPEI in primary health care, in the context of the Brazilian public health system. At leisure time, the cost to move one person to the physically active category at 12 months is estimated in R\$ 369.00 for the BCI and R\$ 426.21 for the SPEI. Our study supports the provision of the BCI as a service in primary care for physically inactive people in Brazil. However, although the BCI seems to be more economic, it is strongly recommended that the two interventions should be offered at primary care in Brazil, since the cost-effectiveness is not that different. Public spending on health can be saved with the implementation of these interventions in other to help the treatment of mellitus diabetes and arterial hypertension. Therefore, further studies concerning the costs of other interventions, with larger populations and more thorough economic analysis are needed.

\section{Collaborations}

CB Papini developed the design of the article, performed the analysis and interpretation of data. L Campos performed the data collection. CB Papini, L Campos, PM Nakamura, BTG Brito and E Kokubun participated in the drafting of the article, final review and critical analysis of the article. 


\section{Acknowledgements}

Conselho Nacional de Desenvolvimento Científico e Tecnológico (CNPq), Physical Activity, Sport and Health Nuclei (NAFES), the Municipal Health Foundation of Rio Claro City, the professionals of Basic Health Units and the participants of the study.

\section{References}

1. Brasil. Ministério da Saúde (MS). Plano de ações estratégicas para o enfrentamento das doenças crônicas não transmissiveis (DCNT) no Brasil: 2011-2022. Brasília: MS; 2011.

2. Schmidt MI, Duncan BB, Silva GA, Menezes AM, Monteiro CA, Barreto SM, Chor D, Menezes PR. Chronic non-communicable diseases in Brazil: burden and current challenges. Lancet 2011; 377(9781):1949-1961.

3. Malta DC, Stopa SR, Szwarcwald CL, Gomes NL, Silva Júnior JB, Reis AAC. A vigilância e o monitoramento das principais doenças crônicas não transmissíveis no Brasil - Pesquisa Nacional de Saúde, 2013. Rev Bras Epidemiol 2015; 18(Supl. 2):3-16.

4. Brasil. Ministério da Saúde (MS). VIGITEL Brasil 2019. Vigilância de fatores de risco e proteção para doenças crônicas por inquérito telefônico. Brasília: MS; 2019.

5. Arredondo A, Zúñiga A, Parada I. Health care costs and financial consequences of epidemiological changes in chronic diseases in Latin America: evidence from Mexico. Public Health 2005; 119(8):711-720.

6. Bahia L, Coutinho ESF, Barufaldi LA, Abreu GA, Malhão TA, Souza CPR, Araujo DV. The costs of overweight and obesity-related diseases in the Brazilian public health system: cross-sectional study. BMC Public Health 2012; 12:440.

7. Malta DC, Bernal RTI, Lima MG, et al. Noncommunicable diseases and the use of health services: analysis of the National Health Survey in Brazil. Rev Saude Publica 2017; 51(Supl. 1):4s.

8. Centers for Disease Control and Prevention (CDC). The Power of Prevention: Chronic Disease...The Public Health Challenge of the 21st Century. Atlanta: CDC; 2009.

9. Lee I-M, Shiroma EJ, Lobelo F, Puska P, Blair SN, Katzmarzyk PT. Impact of Physical Inactivity on the World's Major Non-Communicable Diseases. Lancet 2012; 380(9838):219-229.

10. Anokye NK, Lord J, Fox-Rushby J. Is brief advice in primary care a cost-effective way to promote physical activity? Br J Sports Med 2014; 48(3):202-206.

11. Vijay GC, Wilson ECF, Suhrcke M, Hardeman W, Sutton S, VBI Programme Team. Are brief interventions to increase physical activity cost-effective? A systematic review. Br J Sports Med 2016; 50(7):408-417.

12. Garrett S, Elley CR, Rose SB, O'Dea D, Lawton BA, Dowell AC. Are physical activity interventions in primary care and the community cost-effective? A systematic review of the evidence. Br J Gen Pract 2011; 61(584):e125-e133.

13. Codogno JS, Fernandes RA, Sarti FM, Freitas Júnior IF, Monteiro HL. The burden of physical activity on type 2 diabetes public healthcare expenditures among adults: a retrospective study. BMC Public Health 2011; 11:275.

14. Codogno JS, Fernandes RA, Monteiro HL. Physical activity and healthcare cost of type 2 diabetic patients seen at basic units of healthcare. Arq Bras Endocrinol Metabo 2012; 56(1):06-11. 
15. Monteiro HL, Rolim LMC, Squinca DA, Silva FC, Ticianeli CCC, Amaral SL. Efetividade de um programa de exercícios no condicionamento físico, perfil metabólico e pressão arterial de pacientes hipertensos. Rev Bras Med Esporte 2007; 13(2):107-112.

16. Burini RC, Simonetti LA, Maestá N, Waib PH. Efficiency and costless of a long-term physical exercise program to nom-medicated hypertensive males. $A d v$ Stud Med Sci 2013; 1(3):111-123.

17. Ramos LR, Malta DC, Gomes GAO, Bracco MM, Florindo AA, Mielke GI, Parra DC, Lobelo F, Simoes EJ, Hallal PC. Prevalence of health promotion programs in primary health care units in Brazil. Rev Saude Publica 2014; 48(5):837-844.

18. Gomes GAO, Kokubun E, Mieke GI, Ramos LR, Pratt M, Parra DC, Simões E, Florindo AA, Bracco M, Cruz D, Malta D, Lobelo F, Hallal PC. Characteristics of physical activity programs in the Brazilian primary health care system. Cad Saude Publica 2014; 30(10):2155-2168.

19. Brasil. Ministério da Saúde (MS). Portaria nº 2.488, de 21 de outubro de 2011. Aprova a Política Nacional de Atenção Básica, estabelecendo a revisão de diretrizes e normas para a organização da Atenção Básica, para a Estratégia Saúde da Família (ESF) e o Programa de Agentes Comunitários de Saúde (PACS). Diário Oficial da União 2011; out 21.

20. Rodrigues RCM, João TMS, Gallani MCBJ, Cornélio ME, Alexandre NMC. The "Moving Heart Program": an intervention to improve physical activity among patients with coronary heart disease. Rev Lat-Am Enferm 2013; 21(n. esp.):180-189.

21. Brasil. Ministério da Saúde (MS). Avaliação econômica em saúde: desafios para gestão no Sistema Único de Saúde. Brasília: Editora MS; 2008.

22. Becker L, Gonçalves P, Reis R. Programas de promoção da atividade física no Sistema Único de Saúde brasileiro: revisão sistemática. Rev Bras Ativ Fis Saude 2016; 21(2):110-122.

23. Codogno JS, Turi BC, Kemper HCG, Fernandes RA, Christofaro DGD, Monteiro HL. Physical inactivity of adults and 1-year health care expenditures in Brazil. Int J Public Health 2015; 60(3):309-316.

24. Prochaska JO, Marcus BH. The transtheoretical model: Applications to exercise. In: Advances in Exercise Adherence. Champaign, England: Human Kinetics Publishers; 1994. p. 161-180.

25. Nakamura PM, Papini CB, Teixeira IP, Chiyoda A, Luciano E, Cordeira KL, Kokubun E. Effect on Physical Fitness of a 10-Year Physical Activity Intervention in Primary Health Care Settings. J Phys Activ Health 2015; 12(1):102-108.

26. Hallal PC, Victora CG, Wells JCK, Lima RC. Physical Inactivity: Prevalence and Associated Variables in Brazilian Adults. Med Sci Sports Exer 2003; 35(11):18941900.

27. Garcia LMT, Osti RFI, Ribeiro EHC, Florindo AA. Validação de dois questionários para a avaliação da atividade física em adultos. Rev Bras Ativ Fis Saude 2013; 18(3):317.
28. Moore SC, Lee I-M, Weiderpass E, Campbell PT Sampson JN, Kitahara CM, Keadle SK, Arem H, Gonzalez AB, Hartge P, Adami H-O, Blair CK, Borch KB, Boyd E, Check DP, Fournier A, Freedman ND, Gunter M, Johannson M, Khaw K-T, Linet MS, Orsini N, Park Y, Riboli E, Robien K, Schairer C, Sesso H, Spriggs M, Van Dusen R, Wolk A, Matthews CE, Patel AV. Association of Leisure-Time Physical Activity With Risk of 26 Types of Cancer in 1.44 Million Adults. JAMA Intern Med 2016; 176(6):816-825.

29. Shuval K, Leonard T, Drope J, Katz DL, Patel AV, Maitin-Shepard M, Amir O, Grinstein A. Physical activity counseling in primary care: Insights from public health and behavioral economics. CA Cancer J Clin 2017; 67(3):233-244.

30. Brasil. Ministério da Saúde (MS). Política nacional de promoção da saúde. Brasília: MS; 2006.

31. Rolim L, Amaral S, Monteiro H. Hipertensão e Exercício: custos do tratamento ambulatorial antes e após da adoção da prática regular e orientada de condicionamento físico. Rev Bras Hiperten 2007; 10:2-10.

32. Stevens W, Hillsdon M, Thorogood M, McArdle D. Cost-effectiveness of a primary care based physical activity intervention in 45-74 year old men and women: a randomised controlled trial. Br J Sports Med 1998; 32(3):236-241.

33. Elley R, Kerse N, Arroll B, Swinburn B, Ashton T, Robinson E. Cost-effectiveness of physical activity counselling in general practice. N Z Med J 2004; 117(1207):U1216.

34. Sevick MA, Napolitano MA, Papandonatos GD, Gordon AJ, Reiser LM, Marcus BH. Cost-effectiveness of alternative approaches for motivating activity in sedentary adults: results of Project STRIDE. Prev Med 2007; 45(1):54-61.

35. Agência Nacional de Saúde Suplementar (ANS). Utilização do Sistema Público de Saúde por beneficiários da saúde suplementar [Internet]. [acessado 27 set 2018]. Disponível em: http://www.ans.gov.br/images/stories/Materiais_para_pesquisa/Materiais_por_assunto/benefciarios_sus_2014.pdf.

36. Instituto Brasileiro de Geografia e Estatística (IBGE) [Internet]. [acessado 27 set 2018]. Disponível em: https://ww2.ibge.gov.br/home/estatistica/populacao/ condicaodevida/ams/2009/default.shtm.

37. National Institute for Health and Care Excellence (NICE). Four commonly used methods to increase physical activity: brief interventions in primary care, exercise referral schemes, pedometers and community-based exercise programmes for walking and cycling [Internet]. [acessado 27 set 2018]. Disponível em: http://www.crd.york.ac.uk/crdweb/ShowRecord.asp?ID=32006000250.

38. US Preventive Services Task Force, Grossman DC, Bibbins-Domingo K, Curry SJ, Barry MJ, Davidson KW, Doubeni CA, Epling Jr JW, Kemper AR, Krist AH, Kurth AE, Landefeld CS, Mangione CM, Phipps MG, Silverstein M, Simon MA, Tseng C-W. Behavioral Counseling to Promote a Healthful Diet and Physical Activity for Cardiovascular Disease Prevention in Adults Without Cardiovascular Risk Factors: US Preventive Services Task Force Recommendation Statement. JAMA 2017; 318(2):167-174. 
39. Antunes GA, Tonosaki L, Menezes E, Rech C, Benedetti T, Mazo G. Effect of participation in a behavior modification program on perceived self-efficacy for physical activity. Rev Bras Ativ Fis Saude 2017; 22(6):546-553.

40. Santos CKA, Monteiro GR, Couto JO, Silva RJS. Length of stay of elderly in a Community Physical Activity Program and Associated Factors. Rev Bras Cineanthropom Performance Hum 2017; 19(2):139-149.

41. Leonard T, Shuval K, Oliveira A, Skinner CS, Eckel C, Murdoch JC. Health behavior and behavioral economics: economic preferences and physical activity stages of change in a low-income African-American community. Am J Health Promot 2013; 27(4):211-221.

42. Laine J, Kuvaja-Köllner V, Pietilä E, Koivuneva M, Valtonen H, Kankaanpää E. Cost-Effectiveness of Population-Level Physical Activity Interventions: A Systematic Review. Am J Health Promot 2014; 29(2):71-80.

43. Roux L, Pratt M, Tengs TO, Yore MM, Yanagawa TL, Van Den Bos J, Rutt C, Brownson RC, Powell KE, Heath G, Kohl 3rd HW, Teutsch S, Cawley J, Lee I-M, West L, Buchner DM. Cost effectiveness of community-based physical activity interventions. Am J Prev Med 2008; 35(6):578-588.

44. Plapler PG, Saron TRP, Rezende MUD. Education and Physical Activity in Osteoporosis. J. Osteopor Phys Act 2014; $2: 2$.

45. Townsend N, Wickramasinghe K, Williams J, Bhatnagar P, Rayner M. Physical Activity Statistics 2015 [Internet]. 2015 [acessado 27 set 2018]. Disponível em: https://researchportal.bath.ac.uk/en/publications/ physical-activity-statistics-2015.

Article submitted 23/04/2020

Approved 08/09/2020

Final version submitted 10/09/2020

Chief editors: Romeu Gomes, Antônio Augusto Moura da Silva 